\title{
Restablecer la Armonía: Remedios desde los Pueblos Nasa y Guna para la Sanación de la Madre Tierra
}

\author{
Restore Harmony: Remedies for the Healing of Mother Earth \\ from the Nasa and Guna Peoples
}

Alicia Valeria Zamora Sánchez ${ }^{1}$

\section{Resumen}

La principal fortaleza metodológica del presente trabajo es que se sustenta en los procesos de los pueblos, Guna en Panamá y Nasa en Colombia. Asegura que la palabra dialogue entre comunidades de la región que están librando una batalla por una Madre Tierra que demanda equilibrio y restauración de la armonía y la paz. Representa el sentir popular e indígena, una reflexión desde la experiencia y la simbología propia. Su estilo, estructura y justificación reconfiguran la colonialidad del pensamiento y el conocimiento. ¿De dónde viene la enfermedad que enferma la Pacha Mama?. Es una pregunta que sin duda, tiene origen en los grupos económicos que controlan el capitalismo, industrias extractivas, megaproyectos mineros, hidroeléctricos y petroleros. Para los pueblos indígenas, las compañías petroleras y de gas, leñadores, mineros y empresarios son los causantes de los daños a su territorio, la contaminación de los ríos, la destrucción de la flora y la fauna.

Palabras Clave: Restablecer la armonía; remedios; pueblo nasa; pueblo guna; sanación; madre tierra; pacha mama.

\section{Abstract}

The main methodological strength of this work is that it is based on the processes of Guna People in Panama and Nasa People in Colombia. It ensures that the word dialogue between communities in the region that are fighting a battle for a Mother Earth who demands balance and restoration of harmony and peace. It represents the popular and indigenous feeling, a reflection from experience and its own symbolism. Their style, structure and justification reconfigure the thought and knowledge coloniality. Where does the disease that sickens Pacha Mama come from? It is a question that undoubtedly originates in the economic groups that control capitalism, extractive industries, mining, hydroelectric and oil megaprojects. For indigenous peoples, oil and gas companies, lumberjacks, miners and businessmen are the cause of the damage to their territory, the pollution of rivers, the destruction of flora and fauna.

1 Máster en Comunicación Intercultural con Enfoque de Género y Comunicadora Social. Email: zamora.ali@gmail.com

Recibido: 26/o2/2018 Aprobado: 28/o8/2018 
Keywords: Restore harmony; remedies; nasa people; guna people; healing; mother earth; pacha mama

\section{Introducción}

\section{1.- Nuestro mensaje}

Baba y Nana forjaron a la madre Nabgwana, madre Olobibbirgunyai, madre Ologwadule... Babdummad y Nandummad la crearon hermosa, vestida de verde claro, verde oscuro, tenue y fuerte. Un gran río distribuyó sus aguas sobre ella. El aliento de los vientos era plácido y movía suavemente las hojas de los árboles. Colinas leves y montañas altas se alzaban pausadamente sobre la gran madre. Todo era bello. Los grandes y los pequeños mares, colmados de peces subían y bajaban al ritmo tranquilo de los vientos. Los golfos, las bahías, los arrecifes procuraban un sinfín de peces que no se alejaban de las costas. Las riberas de los ríos brindaban extensos cañaverales y platanares; un sinnúmero de otoes, yucas, camotes rompían la arena fresca de los llano.

La madre estaba viva y necesitaba renovarse. Las flores y toda hierba buena multiplicaban sus sonrisas y aromaban el ambiente. El sol daba su calor según las necesidades de los hijos de la madre Tierra; y así, la luna y las estrellas. Cuando venía la noche, al abatirse el sol, nadie sentía temor de nada.

El hombre y la mujer vinieron sobre nana Ologwadule, Madre Tierra. El hombre y la mujer vinieron con ella. El hombre vino henchido del espíritu de Baba y de Nana, la mujer vino colmada del espíritu de Baba y de Nana. Ellos vinieron para defender a Nabgwana, para cuidar de ella, para sostenerla, para agraciarla, para hacerla productiva.

\section{Algunas claridades sobre este trabajo}

\section{El sueño y de cómo hicimos para construirlo}

Este trabajo representa la entrega de un resultado a las comunidades en lucha. Es un homenaje a los pueblos hermanos, Nasa (en Colombia) y, Guna (en Panamá), que resisten las envestidas del capitalismo. Es el reconocimiento a sus luchas por preservar la vida y el territorio. No pretende ser la explicación exhaustiva de procesos, pensamientos, fenómenos, ni teorías, sino una mirada que recorre e incorpora el sentir indígena y popular, una reflexión desde la experiencia y la simbología propia. Desde la concepción otra, restituye la fuerza de la razón que tienen los pueblos originarios, y desde el pensamiento critico presente en este escrito, emergen con fuerza las sabidurías ancestrales y sus sistemas simbólicos y prácticas tradicionales.

Desde la propia narrativa de los pueblos guna y nasa, queda en evidencia que la cultura occidental no tiene sentido ritual. Por ello, buscamos decir lo esencial: que la 
Madre Tierra, está enferma, que se han ensayado unos remedios que no han resuelto la enfermedad y que se hace necesario buscar otras alternativas.

Este documento, desde su estilo, estructura y justificación intenta romper con la colonialidad del pensamiento y el conocimiento. Es un estudio de la coyuntura mundial desde la sabiduría simbólica guna y nasa. Es la necesidad de comenzar a "colocarse en el lugar epistemológico y desde ahí hacer el diagnóstico" (Hermán Coen). "Los relatos del Babigala, mediante un lenguaje simbólico, nos explican el por qué de Nabgwana, de la realidad de Baba y Nana, del bien y del mal, de la diversidad de pueblos" (Wagua, 2011).

\section{Materiales y métodos}

\section{Los cómos y cuándos}

\section{a. Encuentro con la comunidad}

Junto al pueblo nasa participamos en reuniones y asambleas comunitarias, en mingas de liberación de la Madre Tierra, en ceremonias de armonización y del ritual del Saakhelu para hacer tributos a la Madre Tierra y hacer la armonización de las semillas para la siembra. En Guna Yala, convivimos dentro de la comunidad y junto al Saila Gilberto Arias, fuimos construyendo la ruta de análisis y reflexión para la estructura del documento.

\section{b. Encuentro del tono de voz y la forma en que se va a contar}

Sabemos que es un trabajo para comunidades, por eso, su estructura, su redacción y su didáctica. Es un documento de trabajo para distintos grupos comunitarios y movimientos. Se muestran los hallazgos de la investigación organizados de manera didácticos, cuyas principales referencias teóricas han sido el pensamiento crítico, las luchas populares, indígenas y campesinas.

Para mantener su sencillez también en la estructura, la obra tiene dos únicas partes: i) El cuerpo del documento que es lo que dice la comunidad para sí misma y para el resto del mundo en cuatro capítulos o ramas; y ii) los anexos, que incluyen las notas para explicar con mayor detalle cierta información del texto (que se han puesto al final para que dejen que la lectura fluya lo mejor posible) y los recursos documentales y audiovisuales que han sido parte de las referencias consultadas para este trabajo, no sólo citados, sino adjuntados. 


\section{c. Revisión teórica:}

Los aportes teóricos se basan principalmente en "conversas" con los sabios y sabias del pueblo guna en Panamá y el pueblo nasa de Colombia; así como de distintos momentos de compartir y aprender en distintos rituales y ceremonias sagradas de estos dos pueblos y otros en Centroamérica. Además, se consultaron videos, documentos y libros para armar un marco de análisis y reflexión.

\section{d. Regreso a la comunidad}

El documento, una vez listo, regresa a la comunidad como material educativo para ser compartido entre grupos de jóvenes, mayores y mayoras para generar reflexión, discusión y un nuevo momento de aportes. Es necesario romper con el complejo del producto acabado. El resultado de la investigación debe reflejar el mejor nivel de (auto)reflexión que puedan tener los compañeros y compañeras y su capacidad de hacerse preguntas.

\section{e. Compartir con la palabra}

Desde siempre, escribimos pensando en que la palabra que de aquí saliera, los aportes, debe de llegar a oídos de compañeras y compañeros de movimientos que resisten el capitalismo y se ha dado a la tarea de reflexionar sobre los aportes de las comunidades indígenas y campesinas a la lucha para agrietar el muro.

\section{Resultados y discusión}

\section{Primera rama: El planeta alentado cuando la Tierra puede ser madre}

Cuentan los mayores que hubo hace mucho tiempo el inicio de todo. El antes de todo. "Al inicio, todo era oscuro, una oscuridad tan densa, como si le apretaran a uno los ojos con las dos manos" (Wuagua, 2012, p.8). Cuenta el Babigala que no había ni luna, o estrellas y entonces Baba y Nana se dispusieron a crear la tierra. "La Madre Tierra, nana Ologwadule surgió vigorosa y tierna a la vez" (Wuagua, 2012, p.9). El Saila Gilberto Arias, en su hamaca cantaba que cuando Baba creó para que la Madre Tierra tuviera su hamaca, Baba hizo oro, hierro, plata y cobre. Esto para que la Madre Tierra tuviera fuerza. Debajo de la tierra hizo descansar oro, plata, cobre y hierro para que fueran hamaca de la Madre Tierra. "Baba así lo creó, Nana así lo creo. Baba creó eso primero para sostén de la Madre Tierra. Eso es su fuerza”. (Gilberto Arias, 2016).

Luego Baba y Nana cubrieron el rostro de la madre tierra con cuatro capas de oro azul, amarillo y rojo. Y en cada una de ellas sembró e hizo florecer plantas y flores. Nació el río y de las corrientes brotaron todas las semillas y Ologwadule se llenó de árboles grandes y fuertes. "Germinaron muchos tipos de maíz, de plátano, de yuca, 
de otoe, de camote. Vino todo". Y la tierra se llenó de hijos: de plantas, árboles, flores, ríos... "Ologwadule estaba preparada, vestida, enjoyada" (Wagua, 2011, p.24)

Cuenta el Saila Gilberto (2016) que para cuidar a Nabgwana, cuando ya estaba todo hecho, Baba mandó a Biler y Oloburso. Eran pareja. Baba se fue a niveles superiores y dejó a Biler y a Bursob para cuidar a la Madre Tierra porque ya tenía todo completo. Fueron los primeros, Biler y Bursob. Entonces, Baba le dijo a Biler, Nana le dijo a Biler: "cuando necesites, cuando quieras comer, vienes y me pides, mas no derroches mucho, porque los animales también necesitan comer, los animales también tienen que vivir, ellos también tienen estómago, sienten hambre".

El mayor Manuel Sisco (2005), del pueblo nasa de Colombia, cuenta que en el inicio, existían en el cosmos dos corrientes de viento. Una femenina y otra masculina. Después de correr largo tiempo sin rumbo, ambas corrientes se rozaron y quedaron tan prendidos una del otro que después de formar juntos un gran remolino, se presentaron. Ella, quien traía consigo una vara con un manojo de lana en la punta desde donde ella hilaba y su chumbe asegurando en anaco, dijo: "mi nombre es Uma y soy la mujer que teje la vida". Él, quien portaba en su mano izquierda una vara de mando de oro, contestó: "Yo soy Tay el hombre que construye vida". Después de compartir toda su sabiduría, "Uma y Tay formaron pareja...Y cuentan nuestros mayores que Uma y Tay nos dieron la vida" (Sisco, 2005, p.1).

Uma y Tay dieron a todos los seres, quienes eran antes sólo Taafxi (espíritu, energía, y movimiento), cuerpos físicos o Çxifxi. Y cuentan que de tanta alegría los nasa (es decir, todos los seres de la tierra) comenzaron a pisarse unos a otros. Los más grandes se metían donde estaban los más chiquitos. Hicieron tal desorden que los Nejwe (los creadores, Tay y Uma), mandaron a hermanos mayores para guiar a los nasa, mandaron a los Ksxa'w, la energía de la noche y a los Î'khwe'sx, la energía del día. Pero el desorden siguió, hasta que uno de los Nejwe enojado y con el bastón de autoridad en la mano, los regaño así:

$¡ A$ Ah! ustedes no parecen ser nuestra gente. Ustedes me dan vergüenza, miren como se comportan, miren como se pisan los corazones. Ahora, si quieren tener una casa deben abrazarse, deben quererse...Inmediatamente todos los seres se abrazaron hasta formar una sola masa, como un solo puño y así se formó Kiwe la "tierra", la casa de todos. Kiwe la mujer (Sisco, 2005, p.3).

Dice el relato que la Kiwe fue tomando forma y salían las montañas, los peñascos y se iba poniendo cada vez más bella. Y cuando llegó el tiempo, los Nejwe eligieron a Sek, el sol, como compañero de Kiwe. De ese encuentro nacieron todos los hijos de la Tierra. Todas las especies. 
La tierra al verse rodeada de tantos hijos les aconsejó: Cada uno de ustedes son hijos míos y ahora tienen su sitio para que lo vivan, no olviden ustedes que son criados con el mismo seno, ustedes están prendidos de mí, prendidos del mismo cordón umbilical (Sisco, 2005).

\section{La Tierra solo es posible conocerla en su calidad de madre}

El Saila Gilberto Arias (2016) cuenta que cuando Baba y Nana crearon el mundo, Baba y Nana lo pusieron todo. Pero, ¿Cómo entenderse? Entonces Baba creó un árbol. Nuestros abuelos no tenían calendario, ellos tenían un árbol que Baba puso en la Madre Tierra. En ese árbol, las hojas se ponen amarillas, se caen y entonces ya con ese árbol los abuelos piensan: "llegó el verano o el año nuevo... pasó el año viejo". Cuando llega el invierno, una cigarra canta. Ya Baba la mandó para que los seres humanos se dieran cuenta de cuando iba a llover. Todo eso Baba lo puso, Nana lo puso.

Y así, desde siempre, nuestra Tierra se basa en un equilibrio en el que cada ser tiene un papel que desempeñar y sólo existe a través de la existencia de otro ser. Una sutil armonía. Todo funciona de la forma que debe funcionar.

La vida de los pueblos depende de la vida de la tierra. Abya Yala, o América Latina como la llamaron en la conquista, es el continente que alberga la mayor parte de bosques tropicales del mundo, que en total cubren el 40\% de la superficie de la región. La ubicación de las grandes reservas de bosques del continente coinciden con áreas en las que por herencia ancestral viven y prosperan comunidades rurales y pueblos indígenas.

Sin embargo, cada vez más, estos pueblos se ven amenazados por las industrias extractivas, el narcotráfico, la deforestación, invasión de tierras y megaproyectos mineros, hidroeléctricos y petroleros, por madereros ilegales o políticas de Estado e iniciativas privadas. Los pueblos indígenas ven a las compañías petroleras y de gas, leñadores, mineros y empresarios como "fantasmas de la muerte", porque causan daños en su territorio, contaminan ríos, destruyen la flora y fauna, única fuente de vida conocida por todos.

\section{Historia del Pueblo Guna}

\section{El pueblo de la palabra dulce}

¡Aquellas aldeas redondas rodeadas de mar!

El pueblo Gunadule, o guna como se le conoce normalmente está lleno de una mística inexplicable. Después de la separación entre Colombia y Panamá en 1903, las comunidades quedaron divididas entre los dos países. Actualmente, la mayoría de las 
comunidades vive en Panamá, en más de 360 islas y arrecifes donde poseen colectivamente tres comarcas indígenas: (Guna Yala, Madugandí y Wargandí); en las provincias de Panamá, Colón y Darién; (Hoy son aproximadamente 65 mil personas que viven principalmente en la Comarca Guna Yala.) Las otras comunidades gunadule, viven en Colombia en dos resguardos indígenas: Maggilagundiwala, en español Arquía, ubicado en el actual municipio de Unguía, Departamento del Chocó y Ibggigundiwala, en español Caimán Nuevo ubicado en municipios de Necoclí y Turbo Departamento de Antioquia, sobre la región del golfo de Urabá.

Cuando los ancianos sabios y sabias hablan de la historia de origen del pueblo gunadule siempre remiten a Colombia, porque dicen que venimos de las faldas de las grandes montañas, específicamente del cerro de Dagalgunyala "cerro de platanillo" donde floreció su civilización. Actualmente este cerro queda en el departamento del Chocó y divide a los dos países, Panamá y Colombia. (Green, 2011)

\section{La historia del Pueblo Nasa}

Desde hace muchos años, el valle del río Cauca era hogar de muchos pueblos de Colombia. La gente vivía como quería, como era el mandato de los abuelos y los espíritus, pero para 1535 llegó la conquista y con ella el sometimiento a la tierra libre. Pero con la dominación, nació la resistencia. La Gaitana, una mujer guerrera, se levantó en armas junto a 20 mil guardias indígenas y se enfrentó directamente a los españoles, e instauró durante 120 años la batalla más larga en la historia de Abya Yala que un pueblo dio a los conquistadores. A su legado le siguieron los caciques Juan Tama y Manuel de Quilo Sicos, quienes a través de su malicia y habilidad para negociar llegaron a acuerdos con el imperio español para demarcar un territorio para los indígenas. A estos les llamaron resguardos.

Luego los resguardos fueron invadidos desde la naciente Colombia y volvió la esclavitud y el despojo de las tierras. Pero el pueblo nasa, se levantó junto a Manuel Quintín Lame e iniciaron un proceso de recuperación de tierras en 1971. Unas 120 mil hectáreas en el Cauca. A partir de los pensamientos de Manuel Quintín Lame nace el Consejo Regional Indígena del Cauca (CRIC), la primera organización indígena en el continente. En 1991, después de la masacre a 20 indígenas nasa, se firmaron acuerdos en la Constitución Política de ese año.

Una vez más, el pueblo nasa, comenzó en el año 2005, el proceso de liberación de la madre tierra. 


\section{Segunda rama: Uma Kiwe está enferma}

¿Cuánto tiempo tomó a Baba y Nana, a Uma y Tay, formar la Tierra hasta dejarla como la conocemos? ¿Terminaron su tarea y se escondieron o se fueron a descansar para siempre? ¿La Tierra ya no cambiará más?

La Tierra es un ser vivo que alberga todas las formas de vida que conocemos. Es uno de los ocho planetas que viajan alrededor del Sol. El Sol es uno de los doscientos mil millones (o más) de estrellas de nuestra galaxia y con él giramos a su rededor. Y con la Vía Láctea recorremos el Universo.

El Universo, el gran territorio del espacio del que hacemos parte, tiene casi $14 \mathrm{mil}$ millones de años y al igual que la Tierra, todas sus partes están íntimamente ligadas. También las estrellas son nuestras hermanas, como lo son cada uno de los cuerpos que integran esa gran casa. Nuestra sede, la Tierra, Uma Kiwe, Napguana, Gaia brotó del Universo, de sus mismos materiales, de su crecimiento y de sus ritmos hace unos cuatro mil millones de años.

En la danza de la Tierra, en su vibrar y latido, todos sus hijos e hijas hemos sido tejidos para seguirle el paso. Todos los seres hemos sido creados con la capacidad de escuchar su voz, sentir sus señales, captar sus frecuencias, percibir su frío y su calor. Todos hemos sido creados con la capacidad y necesidad de dejarnos tejer de sus manos, arrullar en sus brazos y alimentar de su seno. Toda la vida en su conjunto, cada trozo y cada ser hace parte de la misma manta. Cada pizca de la vida sostiene la buena salud de la Madre Tierra.

En el tejido de la Tierra los pueblos que la habitamos nos hemos unido a sus puntadas y a su ritmo. Hemos aprendido a nombrarla y a nombrar en distintos lenguajes sus fenómenos y sus misterios. La hemos reconocido como Madre, Mama, Uma, y la hemos nombrado Kiwe, Napgwana, Gaia, Pacha, Terra... Juntarnos a su ritmo nos ha dado todo lo que somos: salud, alimento, sabiduría, gozo. Juntarnos a su ritmo ha permitido que durante los cuatro millones de años que tiene la huella de nuestra especie, la Tierra mantenga su salud, incluso en los últimos cien mil años desde cuando nos tejemos al misterio de enterrar a nuestros muertos y asumirlos como vivos.

Sin embargo, a 14 mil millones de viaje la salud de la Tierra ya no es buena, Gaia está enferma. Kiwe tiene fiebre, sus criaturas se extinguen y la especie humana padece opresión y todos sus derivados. En qué consiste la enfermedad de Nabgwana y cuáles son sus causas es lo que veremos en esta segunda rama del árbol.

Empecemos por reconocer los síntomas o las evidencias en tres grandes enfermedades. 


\section{La Tierra tiene fiebre: el calentamiento global}

La temperatura de la Tierra depende de su buena salud. Como de salud no anda bien la temperatura subió aceleradamente en los últimos años y al subir cambió el clima. Es lo que se conoce como cambio climático. Por eso el calentamiento global y el cambio climático van de la mano. La principal fuente de contaminación de la atmósfera es la gran industria mundial que funciona quemando combustibles que tienen origen en el carbón, el petróleo y el gas y emite millones de toneladas de GEI cada año.

\section{Los seres de la vida están muriendo: extinción de las especies}

El otro gran síntoma de la enfermedad de la Tierra es al extinción de las especies. Nuestro planeta, por ritmos naturales, ha experimentado cinco grandes extinción a lo largo de su historia. Sin embargo, según el estudio "Accelerated modern human- induced species losses: Entering the sixth mass extinction" (Aceleradas pérdidas de especies inducidas por el hombre: Introducción a la sexta extinción en masa) publicado en Science Advanced (2015), establece que ya estamos viendo el comienzo de una sexta extinción masiva de especies.

Así que se trata de extinción de especies y ruptura del tejido. La cadena de la vida se rompe y la compañía de los seres en la algarabía de la existencia se trunca.

Todo está ocurriendo ahora mismo y a ritmos acelerados. Y no se trata solo de la extinción en sí, también se trata de la vía, el camino truncado. En vía de extinción es sinónimo de agonía. Hay especies que están agonizando por la enfermedad de la Tierra. Y para no dejarse morir, las especies se están desplazando.

\section{La gente sufre y muere: crisis humana y humanitaria}

La especie humana somos una de las criaturas de Uma y Tay. No se puede decir que los hijos e hijas preferidos, solo uno más de los seres del tejido vital. Al igual que la ameba, al igual que la yerba y el pavo real, fuimos hechos a su 'imagen y semejanza': de átomos de carbono y los demás elementos de todo el Universo. Al igual que las otras, la especie humana sentimos el agobio y el dolor por la fiebre de Uma Kiwe y por la extinción de las otras especies. En nuestro caso no se trata de nuestra extinción, que no peligra en sí misma, si no del sufrimiento que genera en millones de gentes en todo el mundo la enfermedad de la Tierra y la enfermedad del corazón humano.

Todo está agonizando. Y cuando no haya más aves cruzando el cielo ¿qué será del tejido de la vida? ¿Qué será de la danza cósmica el día que los nukak desaparezcan? Con razón, el jefe Seattle (1855) se pregunta: 
¿Qué resta de la vida si un hombre no puede oír el llorar solitario de un ave o el croar nocturno de las ranas alrededor de un lago?. Yo soy un hombre piel roja y no comprendo. El indio prefiere el suave murmullo del viento encrespando la superficie del lago, y el propio viento, limpio por una lluvia diurna o perfumado por los pinos.

\section{Las causas de la enfermedad}

$¿$ De dónde viene toda esta enfermedad que pone la vida en riesgo? Cuando decimos que el calentamiento global, la contaminación, la extinción de especies tiene origen en causas humanas, ¿quiere decir todos los humanos y las humanas? Puede resultar extravagante que Máxima Acuña en Cajamarca, Perú, tenga la misma responsabilidad que los ejecutivos de la minera Yanacocha. Y sin embargo eso es lo que estamos afirmando cuando decimos "la especie humana daña las lagunas". Entonces, si no somos todos los humanos y las humanas los responsables del daño estructural, ¿de Es la necesidad de comenzar a "colocarse en el lugar epistemológico y desde ahí hacer el diagnóstico” (Hermán Coen).

¿De donde viene la enfermedad?

El saila Gilberto (2016) dice:

Cómo podemos ayudar a la Madre Tierra que está gritando "¿quién me va a ayudar?" ¿Quién le va a comprar la ropa a la madre tierra? ¿Quién le va a comprar el pañuelo a la madre tierra? A la madre tierra le están abriendo el estómago, le están cortando el seno, y todo eso. [...] ¿Quién lo hace? ¿Quién daña? Son la gente grande, la gente que tiene plata. Pero la Madre Tierra está llorando.

La fiebre de la tierra, la extinción de los seres y la muerte y el sufrimiento de la gente tienen todos la misma causa.

Desde los tiempos del sabio Marx a ese mal mayor que es causa de todos los males lo conocemos como capitalismo. Los y las compas zapatistas, en la Sexta Declaración de la Selva Lacandona (EZLN, 2005), haciendo uso de sus propias categorías conceptuales, resumen así la obra de Marx:

El capitalismo es un sistema social, o sea una forma como en una sociedad están organizadas las cosas y las personas, y quien tiene y quien no tiene, y quien manda y quien obedece. En el capitalismo hay unos que tienen dinero o sea capital y fábricas y tiendas y campos y muchas cosas, y hay otros que no tienen nada sino que sólo tienen su fuerza y su conocimiento para trabajar; $y$ en el capitalismo mandan los que tienen el dinero y las cosas, y obedecen los que nomás tienen su capacidad de trabajo. 
En el 2015, los y las zapatistas llamaron al capitalismo "la hidra" en un encuentro en el que plantearon al pensamiento crítico el reto de abordar el capitalismo como ese ser de la simbología griega de muchos tentáculos y cabezas que al cortarle alguno de ellos por ahí mismo se vuelve a regenerar (EZLN, 2015).

Entonces tenemos la causa de la enfermedad de Nagwana ante nuestros ojos. Es un ser que tiene muchos brazos y puede estirarlos tanto como sea necesario para llegar a cada rincón del planeta. El capitalismo ha copado todos los espacios de la vida, no tiene territorios prohibidos. En cada lugar hay proyectos extractivistas de minería, gas, petróleo, madereros, hidráulicos, eólicos, genéticos, viales, de infraestructura, turísticos, agropecuarios. En cada lugar hay instalada una tienda que ofrece todo lo que la publicidad quiere vender.

\section{Cómo funciona La Hidra}

La hidra es el imperio mismo, la manera como el poder transnacional se ha apoderado o controla todo el mundo. Este control global por parte de las empresas es el verdadero rostro de lo que conocemos como globalización. La hidra usa la guerra en función de controlar el territorio (geográfico y el corazón).

\section{¿De dónde viene la enfermedad que enferma la Pacha Mama?}

Sin duda tiene origen en los grupos económicos que controlan el capitalismo, hijos e hijas de Nabgwana que cortaron su ombligo y tomaron otro rumbo.

Llegaron grandes hombres que experimentaron la alegría de ser parte de Nabgwana; pero después se corrompieron, transgredieron las normas de quienes les habían enviado; (...) Cerraron sus corazones y fueron incapaces de ver el valor de las criaturas de Baba y Nana. Atrajeron tiempos de oscuridad, tiempos de ceguera, tiempos de dolor y de mala muerte. Esos primeros defensores de la tierra madre no siguieron los planes de Baba y Nana, se desviaron de sus caminos. (Wagua, 2011, p.32)

El pueblo nasa analiza la enfermedad de la Tierra más allá del control geográfico e incluso, del control del imaginario. Los mayores han advertido que la enfermedad es más profunda. Por eso Gentil Güegia dice que "esa palabra desarrollo ya se nos metió en el corazón" (Güegia, 2016). Dicen los mayores que el corazón nasa (y humano en general) está débil, simple y gorgojeado y por eso la hidra puede regenerarse tan fácil aunque se le corte uno o muchos brazos.

Como veremos en la tercera rama, se han ensayado muchos remedios para aliviar a la humanidad y para aliviar a la Madre Tierra. Consideramos que son las sabidurías 
ancestrales las que tienen la palabra, las que han develado este nuevo territorio de lucha y resistencia.

Es este el punto clave. Todo ocurre dentro del corazón humano. Es el corazón enfermo de capitalismo el que enferma a Nabgwana. Es la hidra capitalista habitando nuestro corazón desde donde puede operar a su antojo. Ese es el gran territorio en disputa. Es el corazón el que da entrada a un proyecto extractivo o el que acepta el nuevo aparato de moda.

\section{Tercera rama: remedios para sanar la enfermedad de Nabgwana}

"Ologanagungiler nos reveló también que además de Abiayala, otras enormes islas había surgido de nana Oloiddirfili. Que algún día llegarían, a nuestras costas, mucha gente de esas islas, que no nos dejarían dormir tranquilos" (Wagua, 2011)

Y tal como Ologanagungiler había dicho al pueblo guna, la conquista llegó a las tierras de Abiayala. De esta manera, se impusieron sobre los pueblos, formas de organización foráneas y opresoras. Se instauraron las colonias y los Estados, para colonizar y dominar. La violencia pasó a ser el instrumento y la dominación pasó a ser hegemonía.

La conquista de Abiayala y el saqueo de África fueron leña para el surgimiento del capitalismo. Desde el principiocomo ahora, está manchado de sangre. La enfermedad poco a poco se extendió por la Tierra y a todos sus hijos e hijas, les llegó la muerte y el sufrimiento.

Sin embargo, como la rebeldía la da la la Madre Tierra desde los primeros tiempos los pueblos se rebelaron a la dominación. Desde entonces hemos buscado remedios que alivien la enfermedad y nuestros pueblos se lanzaron a las guerras contra la conquista, las insurrecciones por la independencia, más tarde a las revoluciones de liberación nacional y ahora último a las revoluciones del socialismo del siglo XXI. Pero en el camino olvidamos aquel vínculo con nuestra Madre Tierra porque eran proyectos por una lado de tipo humanista, herencia de la Ilustración, y por otro de tipo marxista, racionalista y centrado en lo humano. Olvidamos lo que Baba y Nana, Uma y Tay nos habían enseñado tanto para enfrentar como para buscar el remedio.

Al inicio pensamos que era necesario controlar los mismos medios que habían usado los poderosos para la dominación a la hora de contrarrestar el mal. Y así ensayamos un primer remedio: hacer los cambios y las transformaciones desde ese aparato llamado Estado. 


\section{Remedio 1: Cambios desde el Estado: tomarse el Estado o partecitas del Estado}

Los Estados conservaron su carácter opresivo y de dominación hasta el día de hoy. Quijano (citado por Zibechi, 2015) afirma: En América Latina la perspectiva eurocéntrica fue adoptada por los grupos dominantes como propia y los llevó a imponer el modelo europeo de formación de estado-nación para estructuras de poder organizadas alrededor de relaciones coloniales.

El sistema capitalista es como una hidra, dicen los compañeros y compañeras zapatistas. Tiene varias cabezas y ataca por todos los frentes. (...) nos han aprendido hasta nuestros códigos de organización, con los mismos símbolos y el mismo discurso. Son capaces de copiar nuestros métodos, saben la forma de entrar a una comunidad, y de organizar a la gente (Zibechi, 2015).

\section{Remedio 2: Los procesos autonómicos y las resistencias}

Después de levantarse en el 94 y firmar acuerdos con el gobierno que nunca se cumplieron, los compañeros y compañeras zapatistas se dieron cuenta de que ese camino no iba a transformar las bases del sistema. Así que iniciaron la verdadera revolución. Conformaron los caracoles y las juntas de buen gobierno bajo un modelo que se construye desde las comunidades sin intervención del Estado. Han organizado semilleros de pensamiento para reflexionar junto a muchos otros pueblos, compañeros y compañeras, las palabras de las luchas. Están construyendo la autonomía, podemos decir. La autonomía del territorio visible, pero sobre todo la libertad en el pensamiento.

Estas luchas de izquierda, desde abajo y sintonizadas con la Tierra. Surge de la activación política de la existencia colectiva y relacional de una gran variedad de grupos subalternos -indígenas y afrodescendientes, campesinos, pobladores de los territorios urbanos populares, jóvenes, mujeres solidarias. Es la ola creada por los condenados de la tierra en defensa de sus territorios ante la avalancha del capital global neoliberal y la modernidad individualista y consumista.

\section{Remedio 3: Los otros mundos posibles que ya existen. La vida en las comunidades, una alternativa de restauración de la vida en el planeta}

Desde la sabiduría del pueblo guna y del pueblo nasa (así como muchos en Abiayala), se ha sentido en el corazón que la enfermedad no es únicamente para las personas, sino que la opresión, la guerra, el despojo y el dolor es sobre todo para la Tierra como madre, como dadora de vida. El pueblo guna y el pueblo nasa, conocen la enfermedad en toda su dimensión y desde su palabra y su historia, saben también sus causas. 
Todo está controlado, todo está conectado. Cuando nos olvidamos de Baba y Nana, cuando cuando marginamos sus preceptos, cuando aplastamos y destruimos a nuestros aliados como son las plantas, los árboles, los arbustos... es cuando entra el desequilibrio, es cuando el dolor se hace más fuerte que el remedio, y viene la muerte. (Wagua, 2011, p.156)

Cuando las abuelas y los abuelos se olvidaron de su origen que sale de Baba y Nana, y se olvidaron de que pertenecían a la gran familia del Universo, formando parte de toda la naturaleza y de sus relaciones con todos, vinieron maremotos, o el fuego hizo cenizas a nuestras gente, o se desataron devastadores tifones... Así viene nuestro mundo; así camina nuestra historia. (Op. Cit.2011, p.123)

\section{Cuarta rama: El remedio desde el corazón de la tierra en la palabra de sus hijas e hijos}

Lo que vamos a nombrar en este capítulo viene gritando hace siglos. Lo que aquí hacemos es recordarlo, presentarlo para que no siga gritando en vano. A las luchas y movimientos en Abiayala: Hemos leído y aprendido de ustedes, de su vida digna, en principio, pero también del "semillero" que han echado a andar para romper los cercos del pensamiento que nos impiden sabernos desde lo complejo y profundo de nuestras sabidurías y lo sencillo de nuestras vidas.

A esas palabras que se han venido construyendo, es que con mucha humildad, queremos hacer nuestro aporte.

\section{1.- Aprendamos a nombrar nuestra resistencia}

Los caminos que los pueblos han tejido nos han enseñado. Vivimos en tiempos de enfermedad. Ya lo hemos dicho, la Madre Tierra tiene fiebre, está enferma y con ella todos sus hijas e hijos. Y para esto se han buscado remedios. En algunos momentos, el remedio para sanar la injusticia y la opresión parecía convertirse en los otros. En ocupar espacios creados por ellos para sanar el dolor. Pero el caminar de pueblos como el pueblo nasa en Colombia o el pueblo guna en Panamá, nos han enseñado que este no es el camino. Fueron parte, sí. Fueron pasos necesarios para llegar al día de hoy. A todo lo aprendido.

Hoy nos damos cuenta que por mucho tiempo anduvimos por caminos prestados (Güegia, 2015) que nos han alejado de la memoria de nuestros pueblos y de su historia. De su entendimiento de la vida en lo esencial. La resistencia ha sido dura. Hemos entendido nuestras luchas y nombrado nuestra vida desde la lucha de clases que cuenta el sabio Marx; Hemos hecho trincheras para liberarnos de la opresión desde nuestra condición de pobres en contra del poder. Más recientemente, en algunos casos, hemos 
tomado prestado palabras de teorías ajenas para argumentar nuestra lucha por la Madre Tierra. Hemos dicho otro mundo es posible (Dussel, 2014).

Gran parte de los supuestos que utilizamos en este trabajo son la interpretación que ya hizo el pueblo guna o el pueblo nasa del mundo, de la historia y de la vida. Es la teoría desde donde vemos el mundo. Lo que cuenta esa palabra antigua no necesita de interpretación ni aclaración, sino que se convierten en nuestra referencia teórica. Ya es, dada así, una interpretación de la vida desde la espiritualidad y la experiencia de vida de los pueblos. Debe convertirse en nuestra principal teoría para la resistencia.

\section{2.- Entender la enfermedad}

El capitalismo es el causante de todo el desastre que vive el planeta, y la enfermedad es profunda porque el territorio en disputa es el corazón. Es una enfermedad, que vemos con los ojos y la sentimos por todas partes en forma de tres crisis económica, climática y humanitaria. Por ende, no se conquistan los territorios si no se conquista el corazón . Por eso un momento importante para entender la actualidad del capitalismo, su futuro y la forma de vencerlo es introspectivamente mirando el corazón como un ser social y comunitario (Dorado, 2015).

\section{3.- El remedio, al corazón es necesario bañarlo con medicina}

Se ha dicho por los y las liberadoras de la Madre Tierra del pueblo nasa (2016) que sanar la enfermedad de la tierra, depende de sanar el corazón de nosotros sus hijas e hijos.

Esto puede ser un primer paso más coherente para poder enfrentar los otros desafíos. De ahí también que el gran paso que empecemos a dar y que durará muchos años sea sobretodo espiritual. Será la espiritualidad, la revisión del corazón y su reconexión con el ombligo de la Madre Tierra el principal tratamiento para sanar el planeta. De allí la importancia en entender que nuestros pueblos cantan desde hace mucho tiempo el remedio. Sencillo y profundo. En palabras del Saila Jaime Meléndez (2010), las condiciones para la vida en armonía son reconocer que: "Todos los seres son vivos. Todos los seres somos hermanos. Todos los pueblos somos hermanos. La Tierra es nuestra madre".

\section{4.- La griega, el muro y lo que hay detrás del muro.}

"Observemos esta otra casa, la choza grandísima que nos cubre, el firmamento, el universo. Ninguno en ella trabaja solo, todos trabajan unidos. Por eso no se acaba. Cuando empiecen a trabajar divididos, vendrá la destrucción. El huracán más temible, que destruye casas y sembrados, no tiene fuerza si el mar y la lluvia no le dan la mano, no lo empujan. El sol, las estrellas, todos trabajan unidos. Nadie dice que es 
más grande, más fuerte que los demás. Nadie excluye a nadie. Nadie se siente con más poder y fuerza que los demás. Así debemos ser. Nosotros estamos rodeados de peligros. Nos rodean por todas partes; y sólo unidos fuertemente vamos a poder seguir en nuestra comunidad. Baba lo quiere así. Y nosotros, para poder vivir en esta madre tierra, también lo queremos así. Lo necesitamos”. (Wagua, 2011)

El desconocimiento y el rechazo a las culturas, según los abuelos gunas, no han traído más que impotencia e incapacidad de salvar a la tierra como Madre, que poco a poco se está muriendo, porque la carga que debe ser redistribuida en todos los hombros de los seres que conformamos el pluriverso, está recayendo más violentamente en sólo algunos.

Los compañeros zapatistas cuentan que el capitalismo es un gran muro, que hay que destruir para poder ver la alternativa. Los principios y la palabra originaria representan actualmente un aporte para la restauración de la Madre Tierra. Sus vidas es el mañana. La vida de estos pueblos y de muchos en el mundo, ya son las alternativas.

\section{Conclusiones}

Hemos entendido la resistencia como un gran árbol de dos ramas: la primera rama, como "freno de emergencia", donde cotidianamente las comunidades están en la defensa y la lucha frente al despojo de los territorios y los proyectos privados o estatales. Y la segunda, como "alternativas vivientes", en la construcción de estrategias y modelos comunitarios que nacen de las claridades políticas y espirituales; y en la protección de la vida como es, la simbología y las formas de comunicación propias que constituye el rostro real, los otros mundos que ya existen.

Una vida (individual o colectiva) que se construya a partir de ese postulado es la resistencia y la crítica más profunda al ejercicio del poder y la autoridad del Estado, a la opresión y a la distancia que promueven las lógicas neoliberales e imperiales, a la privatización de los recursos, la mercantilización generalizada y la explotación de la tierra.

El desconocimiento y el rechazo a las culturas, según los abuelos gunas, no han traído más que impotencia e incapacidad de salvar a la tierra como Madre, que poco a poco se está muriendo, porque la carga que debe ser redistribuida en todos los hombros de los seres que conformamos el pluriverso, está recayendo más violentamente en sólo algunos. 


\section{Lista de referencias}

Bogotá, colombia: Ediciones desde abajo de la que fue gerente el vicepresidente Richard Cheney.

Canal 6 de Julio [Canal6deJulio] (2016, Enero 29). Zapatistas: Crónica de una RebeliónEZLN [HD] [Documental Completo] - Canal 6 de Julio [Archivo de video]. Recuperado de https://www.youtube.com/watch?v=lGSboNzGpUI

Comisión sexta del EZLN. (2015). El pensamiento crítico frente a la hidra capitalista.

Comité Clandestino Revolucionario Indígena Comandancia General del Ejército Zapatista de Liberación Nacional. (2005). Sexta declaración de la selva lacandona. Enlace Zapatista. Recuperado de: http://enlacezapatista.ezln.org.mx/sdsl-es/

Dussel, E. (2014). Otro Mundo sí es Posible. Tesis de Economía Política. Recuperado en: https://www.youtube.com/watch?v=4LngCCiSiNc\&spfreload=10 .

Green, A. (2011). Tesis doctoral: Significados de vida: espejo de nuestra memoria en defensa de la madre tierra. Universidad de Antioquia, Medellín.

IPCC, 2014: Cambio climático 2014: Informe de síntesis. Contribución de los Grupos de trabajo I, II y III al Quinto Informe de Evaluación del Grupo Intergubernamental de Expertos sobre el Cambio Climático [Equipo principal de redacción, R.K. Pachauri yL.A. Meyer (eds.)]. IPCC, Ginebra, Suiza, 157 págs.

Jefe Seattle (1855). [Carta dirigida a Franklin Pierce, presidente de los Estados Unidos en ese tiempo] Recuperado en: http://ciudadseva.com/texto/ carta-del-jefe-seattle-al- presidente-de-los-estados-unidos/

Marx, C. (1867). Capitulo XXIV: La llamada acumulación originaria. En Marx, C. (Ed) El Capital. Recuperado en: https://www.marxists.org/espanol/m-e/186os/ eccx86s.htm

Wagua, Aiban. (2007). Así lo vi y así me lo contaron: datos de la Revolución Guna de 1925, versión del Sagladummad Inakeliginya y de gunas que vivieron la revolución de 1925. (comp. y trad.). Panamá.

Wagua, Aiban. (2011). En defensa de la vida y su armonía. Elementos de la religión kuna. Textos del Bab Igala (comp. y trad.). Kuna Yala, Panamá: Emisky.

Zibechi, R. (2015). Descolonizar el pensamiento crítico y las prácticas emancipatorias. 